\title{
Controlled Release from Core-Shell Nanoporous Silica Particles for Corrosion Inhibition of Aluminum Alloys
}

\author{
Xingmao Jiang, ${ }^{1,2}$ Ying-Bing Jiang, ${ }^{3}$ Nanguo Liu, ${ }^{4}$ Huifang Xu, ${ }^{5}$ Shailendra Rathod, ${ }^{1}$ \\ Pratik Shah, ${ }^{1}$ and C. Jeffrey Brinker ${ }^{1,6}$ \\ ${ }^{1}$ Department of Chemical and Nuclear Engineering and Center for Micro-Engineered Materials, \\ University of New Mexico, Albuquerque, NM 87106, USA \\ ${ }^{2}$ Aerosol and Respiratory Dosimetry Program, Lovelace Respiratory Research Institute, 2425 Ridgecrest Dr. SE, \\ Albuquerque, NM 87108, USA \\ ${ }^{3}$ Transmission Electron Microscopy Labs, The University of New Mexico, Albuquerque, NM 87131, USA \\ ${ }^{4}$ SCB Innovation Accelerator, Dow Corning Corporation, 2200 W. Salzburg Road, P.O. Box 0994, Midland, MI 48686, USA \\ ${ }^{5}$ Department of Geoscience, University of Wisconsin-Madison, Madison, WI 53706, USA \\ ${ }^{6}$ Advanced Material Laboratory, Sandia National Laboratories, Albuquerque, NM 87185, USA \\ Correspondence should be addressed to C. Jeffrey Brinker, cjbrink@sandia.gov
}

Received 3 November 2010; Accepted 2 December 2010

Academic Editor: Hugh D. Smyth

Copyright ( 2011 Xingmao Jiang et al. This is an open access article distributed under the Creative Commons Attribution License, which permits unrestricted use, distribution, and reproduction in any medium, provided the original work is properly cited.

Cerium (Ce) corrosion inhibitors were encapsulated into hexagonally ordered nanoporous silica particles via single-step aerosolassisted self-assembly. The core/shell structured particles are effective for corrosion inhibition of aluminum alloy AA2024-T3. Numerical simulation proved that the core-shell nanostructure delays the release process. The effective diffusion coefficient elucidated from release data for monodisperse particles in water was $1.0 \times 10^{-14} \mathrm{~m}^{2} \mathrm{~s}$ for Ce $\mathrm{e}^{3+}$ compared to $2.5 \times 10^{-13} \mathrm{~m}^{2} \mathrm{~s}$ for NaCl . The pore size, pore surface chemistry, and the inhibitor solubility are crucial factors for the application. Microporous hydrophobic particles encapsulating a less soluble corrosion inhibitor are desirable for long-term corrosion inhibition.

\section{Introduction}

Controlled release is of particular interest for a broad spectrum of studies dealing with corrosion inhibition, fertilizers, and medical applications such as gene delivery, tissue engineering, and diagnostic agents. Long-term cost-effective corrosion inhibition of steels and alloys requires a controlled release of corrosion inhibitors especially for protecting the aluminum alloy AA2024-T3 used in aeronautic applications [1]. AA 2024 is composed of (in weight percentage) 93.5\% Aluminum ( $\mathrm{Al}), 4.4 \%$ Copper $(\mathrm{Cu}), 0.6 \%$ Manganese $(\mathrm{Mn})$, and $1.5 \%$ Magnesium $(\mathrm{Mg})$. Currently, carcinogenic chromate compounds have been widely used as corrosion inhibitors [2, 3], but these are expensive to process and maintain. The most potent and less toxic candidate inhibitors for aluminum alloys, according to the study by Scully's group and Tailor's group, are lanthanide, metavanadate, molybdenum, and cobalt ions $[1,4]$. The inhibitors not only suppress cathodic reactions in the alloys that are essential for corrosion inhibition and copper replating, but they provide self-healing for the alloys as well. Much effort has been made to investigate corrosion inhibition, ranging from barrier to conversion coatings or pigmentation of the inhibitors [5-8]. Layered clays have been tried for encapsulating the inhibitors by ion exchange [9]. A multifunctional organic coating containing silica can be formed by the in situ sol-gel process. However, this method lacks appropriate storage and slow release of corrosion inhibitors [10-13]. Nanoporous silica is a mechanically and thermally stable, cheap, and an environmentally benign ceramic, and it has found various applications in adsorption, separation, and catalysis [14, 15]. The well-controlled pore size, narrow pore size distribution, and controllable functionality and pore surface chemistries of self-assembled nanoporous silica materials suggest their use as the encapsulating material for controlled release of corrosion inhibitors. The promising nanocapsules can be 


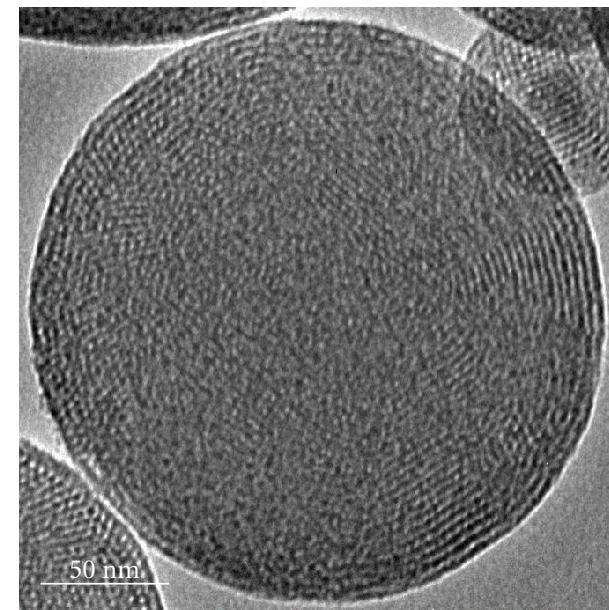

(a)

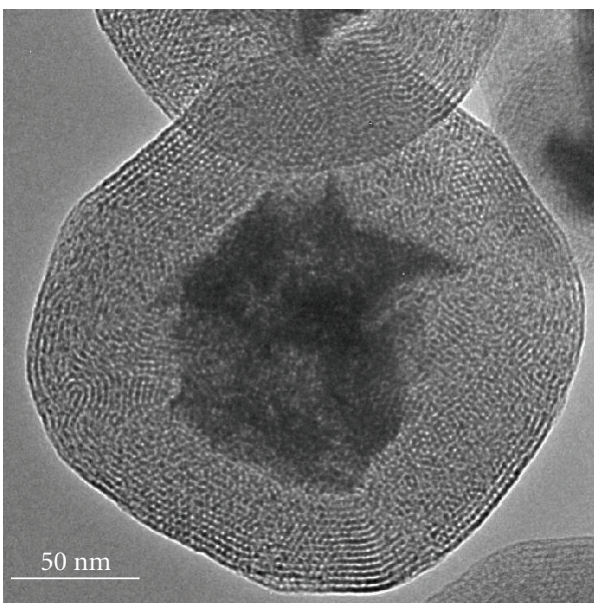

(c)

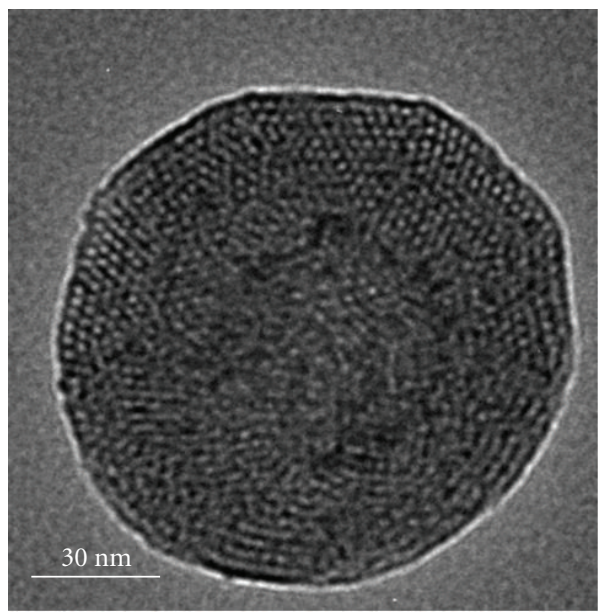

(b)

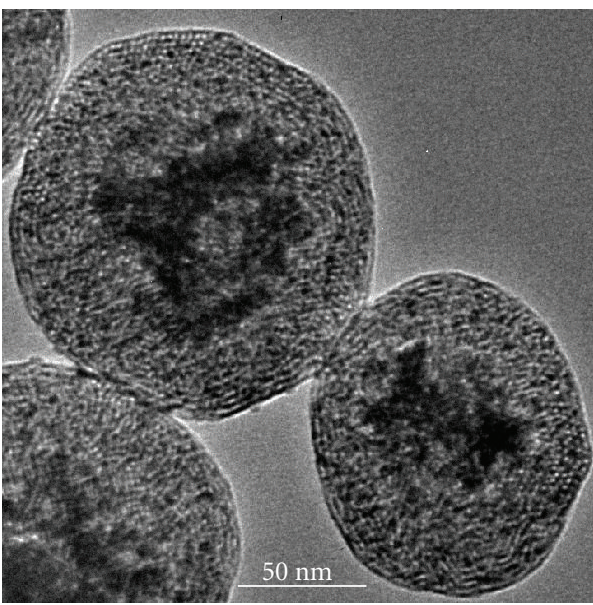

(d)

FIGURE 1: TEM images of nanostructured particles (a-d) with different loadings of Ce. The molar ratios of the precursor sol compositions are TEOS : $\mathrm{EtOH}: \mathrm{H}_{2} \mathrm{O}: \mathrm{HCl}: \mathrm{CTAB}: \mathrm{CeCl}_{3}=1: 7.7: 24.8: 0.00125: 0.18: x$, where $x=0,0.06,0.12$, and 0.18 , respectively, for particle samples (a)-(d).

dispersed as pigments into a protective epoxy coating for a long-term cost-effective protection of the alloys.

In this paper, we report a novel single-step method for encapsulating cerium (Ce) corrosion inhibitors into nanoporous silica particles by aerosol-assisted evaporationinduced self-assembly (EISA). Nanostructured particles with a core of Ce compounds and a shell of ordered nanoporous silica were prepared. These core-shell nanostructured particles are effective for inhibiting corrosion of aluminum alloy AA2024-T3. We investigated the controlled release of inhibitors and found that long-term corrosion inhibition can be realized using hydrophobic microporous nanocapsules.

\section{Results and Discussion}

The core-shell nanostructured particles were synthesized via aerosol-assisted EISA using cetyltrimethylammonium bromide $(\mathrm{CTAB})$ as a structure-directing agent. Figure 1 shows representative transmission electron microscopy (TEM) images of calcined silica particles. At low Ce loading the particles keep a hexagonally ordered mesoporous silica structure featuring parallel aligned stripes and hexagonally arranged pores (Figure 1(a)), reflecting differing orientations of a 2D hexagonal silica mesophase confined within a spherical shell. By increasing the loading of cerium chloride $\left(\mathrm{CeCl}_{3}\right)$, the mesostructure turns into a core-shell structure (Figures 1(b) and 1(c)). At high loading (Figure 1(d)), the particles became worm-like or even less ordered, especially near the particle center.

Core-shell structured sample $\mathrm{c}$ has been characterized by $\mathrm{X}$-ray diffraction (XRD) and nitrogen isothermal sorption. The nitrogen sorption isotherm of the nanostructured core-shell Ce/silica particles shown in Figure 2 was measured using liquid nitrogen at $77 \mathrm{~K}$ and yielded a type IV isotherm with a very narrow hysteresis loop, typical of hexagonal MCM-41-like mesoporous silicas. The pore size was determined to be $1.95 \mathrm{~nm}$ with a narrow distribution using 


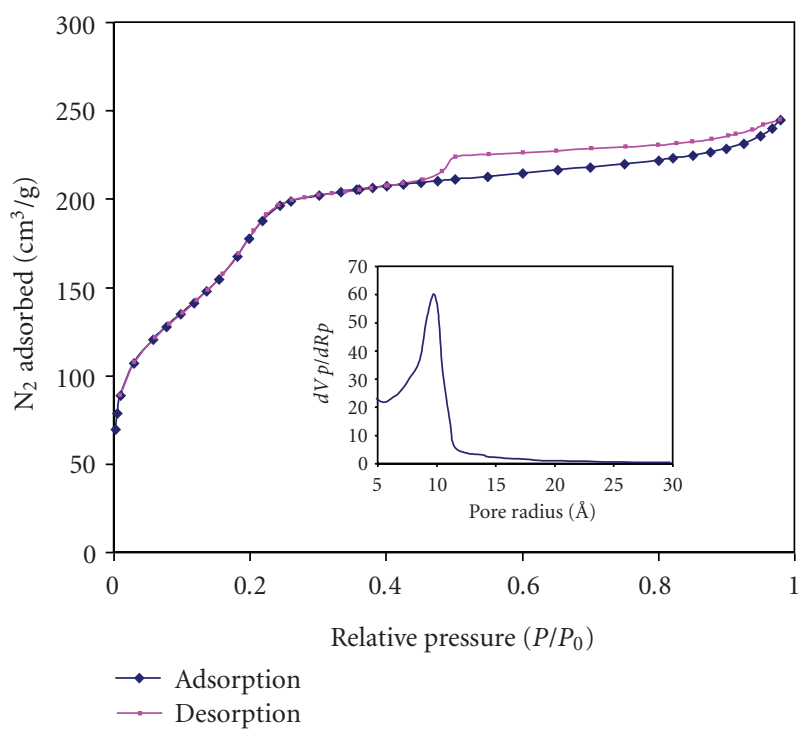

FIGURE 2: Nitrogen sorption for core-shell mesoporous particle b (Figure 1). Inset shows the $\mathrm{BJH}$ pore size distribution.

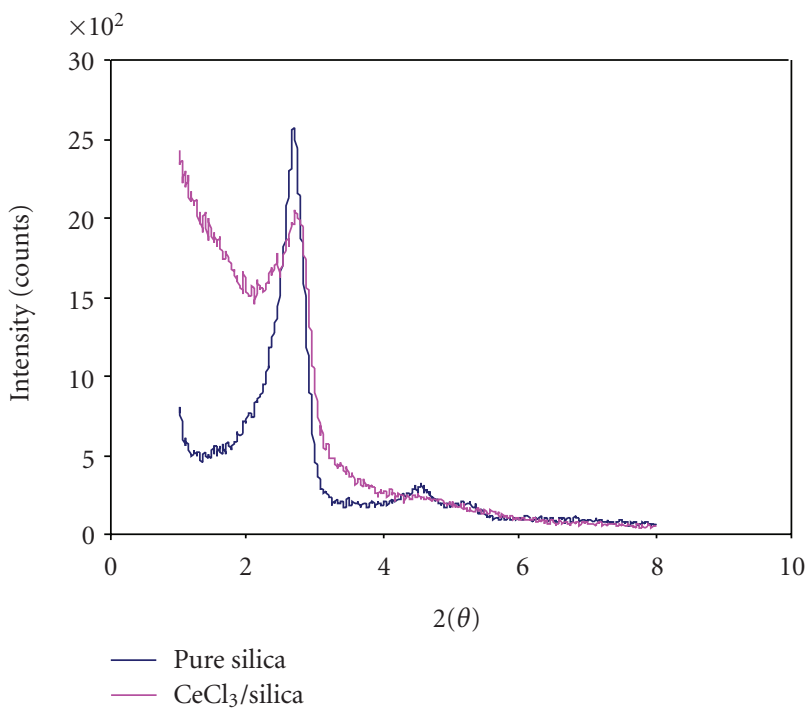

FIGURE 3: XRD patterns for sample a (pure silica) and sample c (Figure 1).

the Barrett-Joyner-Halenda (BJH) model. The BrunauerEmmett-Teller (BET) surface area is $615 \mathrm{~m}^{2} / \mathrm{g}$. The low-angle peaks are associated with the $2 \mathrm{D}$ hexagonal silica mesophase. As can be seen from the XRD patterns shown in Figure 3, compared to pure mesoporous silica the mesostructural order for sample c (Figure 1) is reduced as measured by less intense diffraction peaks.

The TEM image and the energy-filtered elemental TEM maps of $\mathrm{Ce}$ and silica for particle sample $\mathrm{c}$ are shown in Figure 4 and clearly reveal that $\mathrm{Ce}$ is located mainly at the core. The core is composed of mostly Ce compounds combined with a little amount of silica. The surrounding crust contains less $\mathrm{Ce}$, and it is dominantly composed of silica.

A high resolution TEM image (Figure 5) for the core of a nanostructured particle shows that the core is composed of multiple crystallites $\sim 3 \mathrm{~nm}$ in size. The inset selected area electron diffraction pattern (SAED) evidences the nanocrystalline cubic $\mathrm{CeO}_{2}$ structure. $\mathrm{CeCl}_{3}$ is easily hydrolyzed and further oxidized into $\mathrm{Ce}$ dioxide at high temperature. Figure 6 shows the energy dispersive X-ray (EDX) spectrum for the particle sample, indicating that most of the $\mathrm{CeCl}_{3}$ has been hydrolyzed and the $\mathrm{Cl} / \mathrm{Ce}$ ratio is much less than the stoichiometric value of 3 . The existence of various forms of Ce compounds and the cocondensation of hydrolyzed Ce species with silica acid limit the growth rate of crystallites and favor the formation of multicrystals instead of single crystals within the particles. Hence, the particle samples showed different colors, varying from white, purple, to yellow, with the increasing oxidation. As shown in Figure 7, the electron paramagnetic resonance experiment (EPR) for sample $c$ (Figure 1) proved that only $32 \%$ of the $\mathrm{Ce}$ is in the state of $\mathrm{Ce}^{3+}$. Care should be taken to keep the system from air during aerosol generation and succeeding calcination.

The evaporation of solvents, condensation kinetics, and the mass and heat transport together determine the final structure and the morphology. To better understand the formation process of the core-shell structure, the $\mathrm{HCl}$ concentration in precursor sol was intentionally increased 10 times for sample $c$, and the as-synthesized particles have an inner hollow structure composed of Ce compounds as shown in Figure 8. The reduced Ce salt solubility and quicker condensation/gelation due to accelerated hydrolysis and condensation under more acidic condition impede the ions' diffusion and seize the formed Ce salt crystallite before the ions diffuse inward along with the receding aqueous phase (effective aqueous diffusion coefficient for $\mathrm{CeCl}_{3}$ in CTAB-templated mesoporous silica is estimated at $\sim 1.0 \times 10^{-14} \mathrm{~m}^{2} / \mathrm{s}$ at $25^{\circ} \mathrm{C}$ ). For comparison, a silica-free dilute ethanol solution of $\mathrm{Ce}\left(\mathrm{NO}_{3}\right)_{3} \cdot 6 \mathrm{H}_{2} \mathrm{O}$ with a molar ratio of $664 \mathrm{EtOH}: 1 \mathrm{Ce}\left(\mathrm{NO}_{3}\right)_{3} \cdot 6 \mathrm{H}_{2} \mathrm{O}$ was also sprayed into the particle-generating system as the precursor sol. Even though no silica species existed, the much lower solubility of $\mathrm{Ce}\left(\mathrm{NO}_{3}\right)_{3} \cdot 6 \mathrm{H}_{2} \mathrm{O}$ in ethanol than in water and the much quicker evaporation of the more volatile ethanol in the absence of a silica network accounted for the early nucleation and succeeding crystallization. Decomposition of the salt and Oswald ripening during aerosol particle generation and succeeding calcination rendered the hollow particles spherical and uniform in thickness (Figure $8(\mathrm{a})$ ). The hollow spherical particle size and the thickness depend on the precursor composition, salt type, and the solvent evaporation rate. Further calcination of the particles makes hollow spherical $\mathrm{Ce}$ oxide or $\mathrm{Ce}$ dioxide, depending on the calcination environment. A less volatile good solvent and lower heating temperature help form smaller hollow spherical particles of a thicker Ce species layer or even form solid Ce species particles. Figure 9 shows a snapshot of an aerosol particle collected at the end of a $200^{\circ} \mathrm{C}$ heating glass tube by a cryofinger kept at $77 \mathrm{~K}$. With the evaporation of the solvents and a growing silica/surfactant gel layer, liquid sol recedes toward the droplet's center, and the silica/surfactant crystal phase starts the EISA into the ordered mesostructures.

A mechanism for the formation of the core-shell nanostructure is proposed here. Starting from an homogeneous 


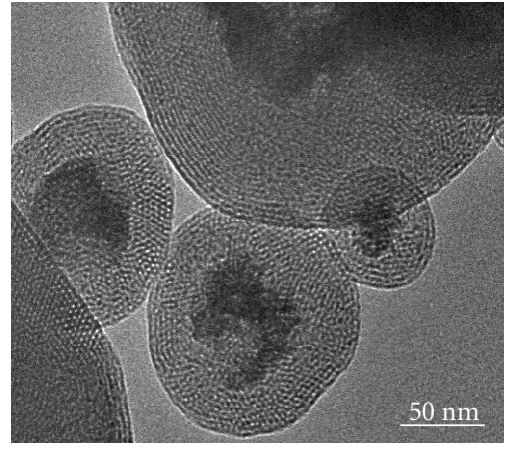

(a)

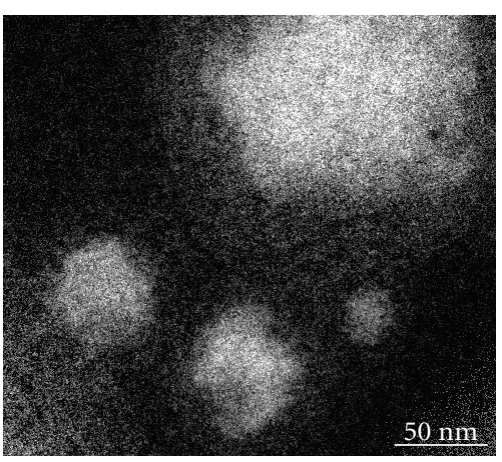

(b)

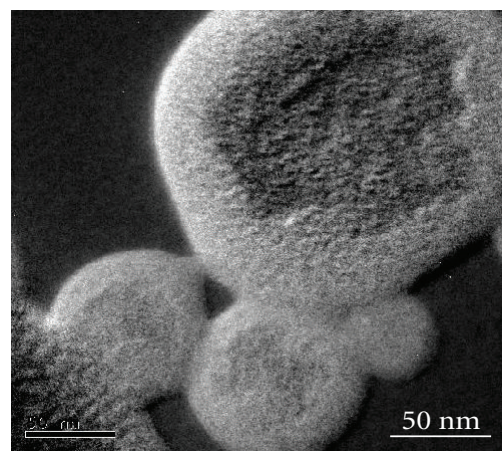

(c)

FIGURE 4: (a) TEM image, (b) energy-filtered Ce map, and (c) energy-filtered silica map for core-shell structured particle sample c (Figure 1).

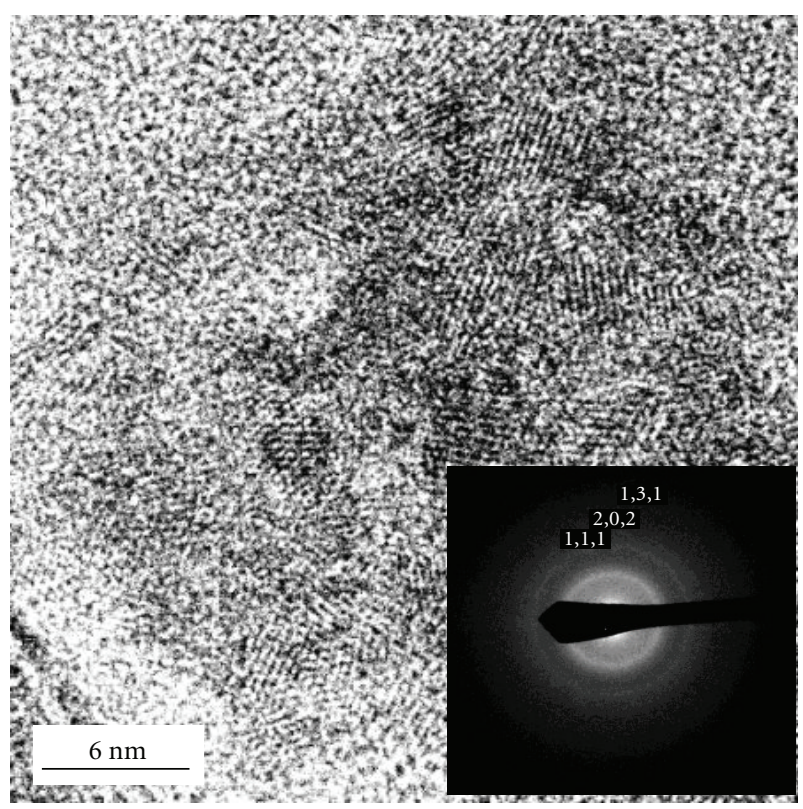

Figure 5: High resolution TEM image for the core part of nanostructured particle (inset is selected area electron diffraction (SEAD) pattern).

solution with the initial $\mathrm{CTAB}$ concentration much less than critical micelle concentration (CMC), the evaporation of solvents within each droplet creates growing radial gradients in surfactant, solvent, and salt concentrations that keep maximum concentrations for the surfactant and Ce salt at the droplet surface, resulting in an inward diffusion of the salt and surfactant and outward diffusion of solvents. The relatively lower mobility of surfactant due to the high molecular weight and the strong interaction (electrostatic and/or hydrogen bonding) with the silica network causes an inward drift of Ce species relative to the silica/surfactant phase of the droplet's core along with the receding aqueous phase. CMC is first exceeded at the droplet surface after a certain evaporation time. Once that happens, the CMC location continuously moves to the core of the droplet throughout the course of the EISA process. The surfactant enrichment induces silica-surfactant self-assembly into

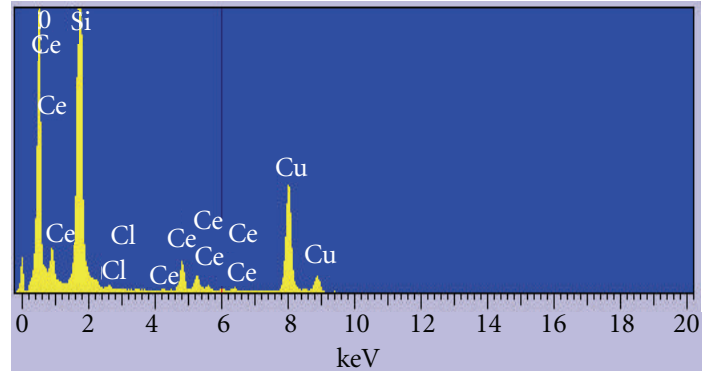

FIGURE 6: EDX spectrum of the core-shell particles observed on the surface of a carbon-coated copper grid.

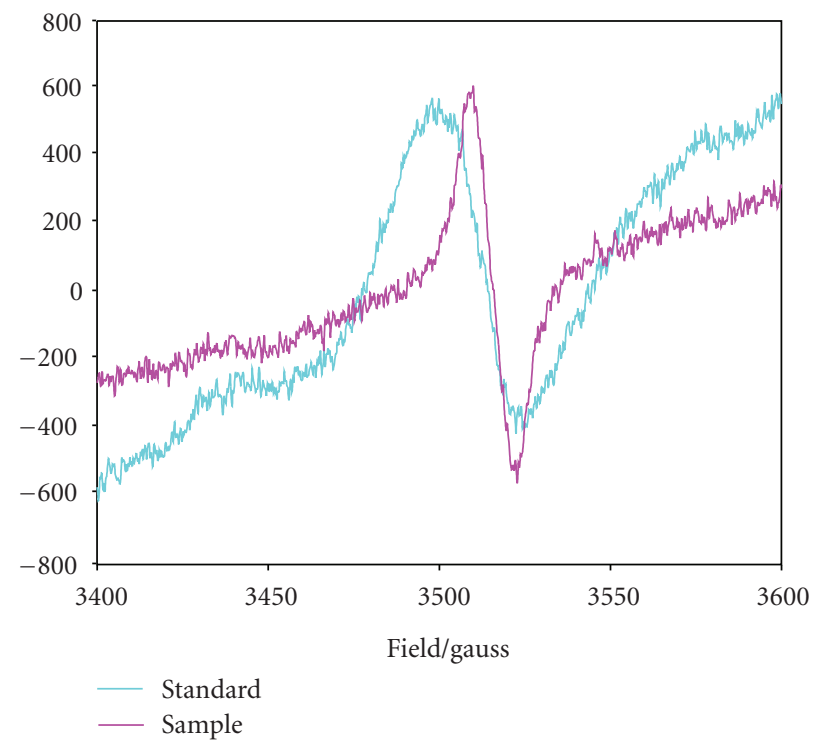

Figure 7: EPR spectra for $\mathrm{CeCl}_{3}$ standard and particle sample c (Figure 1).

micelles and their further organization into liquid-crystalline mesophases. The receding liquid-vapor interface causes silica-surfactant liquid-crystalline domains to grow radially inward, leaving a growing CTAB-templated liquid-crystalline 


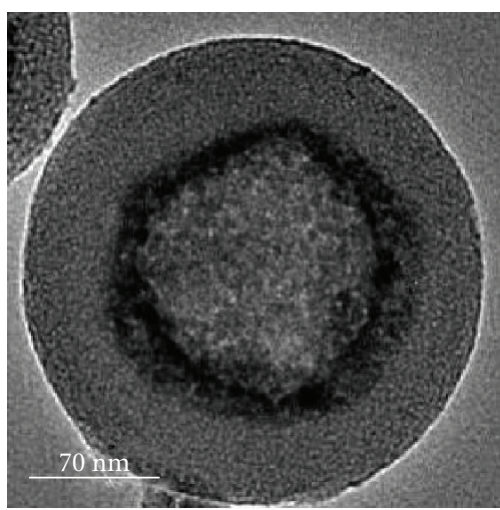

(a)

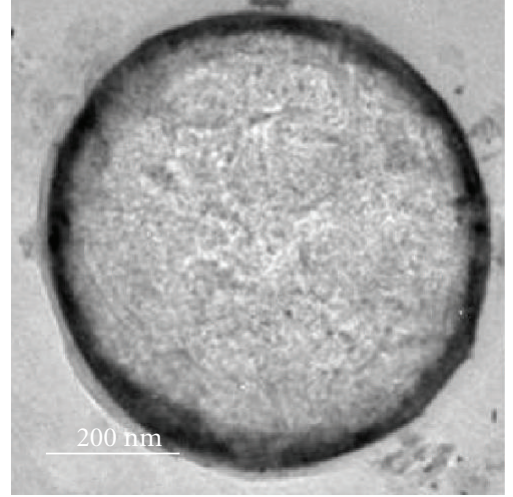

(b)

Figure 8: TEM images. (a) Hollow Ce/silica particle synthesized using precursor sol with molar ratio $\mathrm{TEOS}: \mathrm{EtOH}: \mathrm{H}_{2} \mathrm{O}: \mathrm{HCl}$ : CTAB $: \mathrm{CeCl}_{3}=1: 7.7: 24.8: 0.0125: 0.18: 0.18$. (b) Hollow Ce oxide particles.

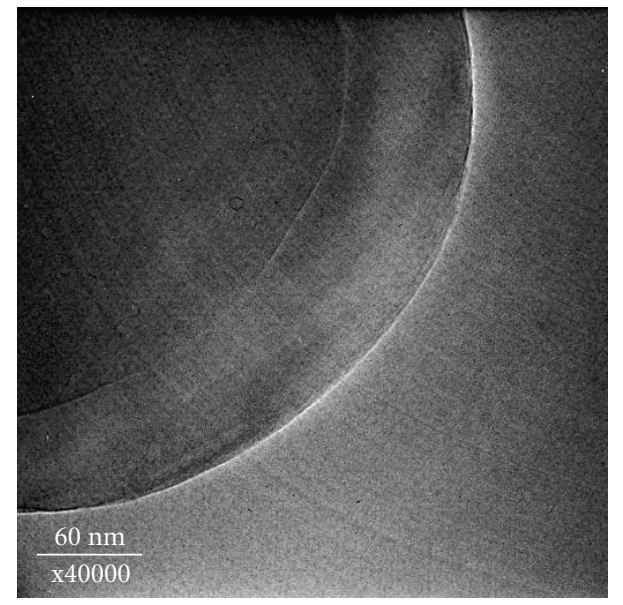

FIGURE 9: TEM image of a frozen evaporating droplet collected on a TEM copper grid by a cryofinger kept at $77 \mathrm{~K}$.

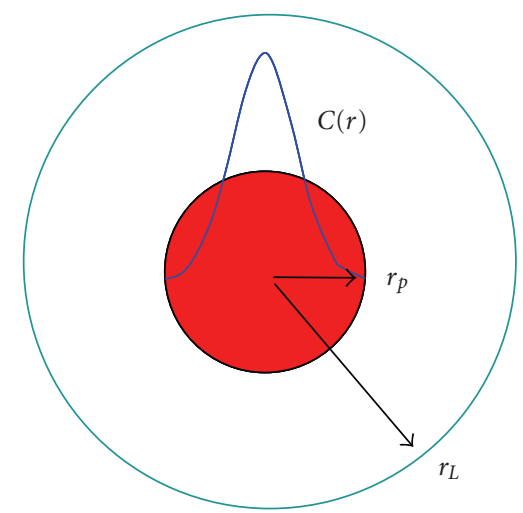

Scheme 1: Schematic of particle and droplet for diffusion.

state. The evaporation and resulting inward moving liquidvapor interface boundary concentrate the salt solution. The partitioning of $\mathrm{CeCl}_{3}$ in the CTAB-templated liquidcrystalline state is quite lower than that in the aqueous phase.

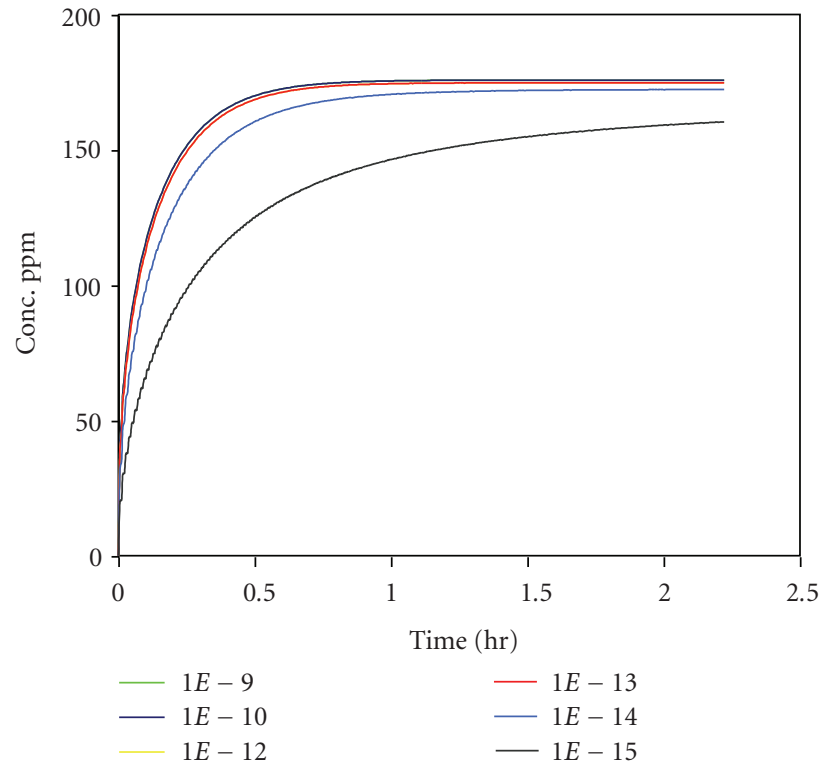

Figure 10: Effect of external diffusion $\left(D_{S}\right)$ on the release process.

As evaporation proceeds, part of the Ce salt is hydrolyzed into a less soluble Ce hydroxide due to the increased temperature and steep temperature gradient. Hydrolyzed Ce species may take part in the cocondensation along with the silica species. To a point of evaporation, less soluble Ce species nucleate and precipitate. The salt crystallites cannot grow into a big single crystal in the presence of other Ce species as impurity. The oversaturated Ce chloride and Ce hydroxide nucleate and precipitate are collected/filtered by increasingly dense liquid-crystalline mesophases. The heldup Ce species undergo continued hydrolysis and have a higher tendency to be hydrolyzed than the inner salt does due to the steep temperature gradient. However, they cannot continue to grow because of the limited Ce source and existence of the well-assembled bi-continuous CTAB/silica liquid-crystal phase. EDX data prove that smaller particles 


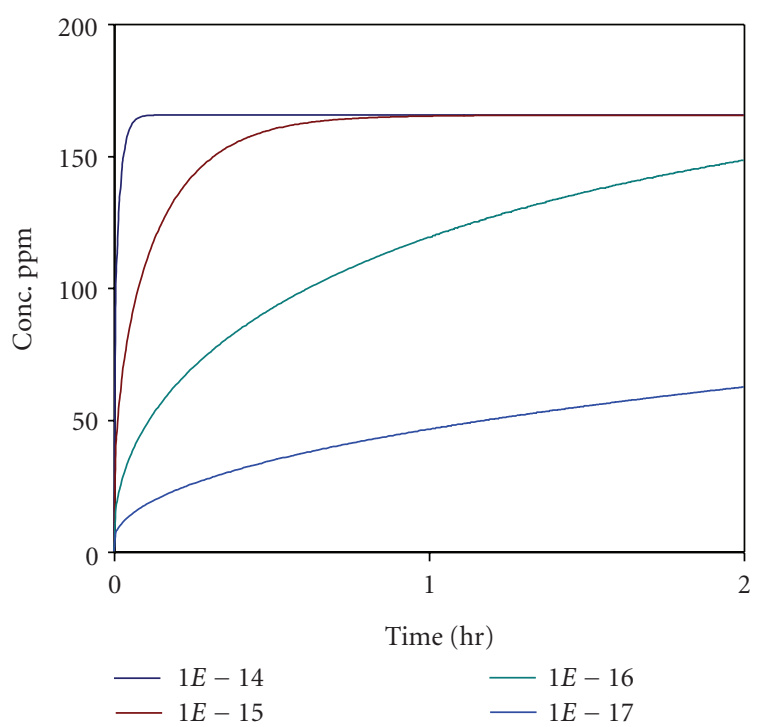

Figure 11: Effect on internal diffusion $\left(D_{P}\right)$ on the release process.

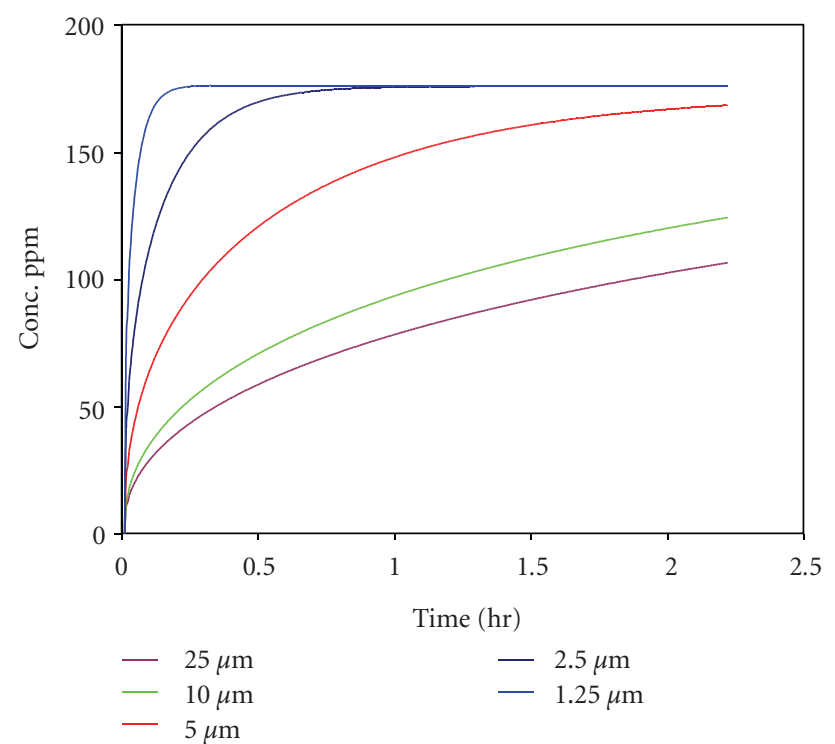

FiguRE 12: Effect of particle size on the release process at a dilution level of 100 and $D_{S}=1 \times 10^{-10} \mathrm{~m}^{2} / \mathrm{s}, D_{P}=1 \times 10^{-15} \mathrm{~m}^{2} / \mathrm{s}$.

have a higher $\mathrm{Ce} / \mathrm{Cl}$ ratio, and the ratio is lower at the center than at the crust. At the final period of evaporation, the vapor-liquid boundary shifts to the core. With the increasing temperature and salt concentration, Ce salt nucleation and crystal growth continues and causes phase separation of the mixture. Bigger Ce chloride/Ce hydroxide crystallites are formed at the center. The crystallites distort the assembled liquid-crystal phase and make the mesostructured silica less ordered at the center.

2.1. Mathematical Modeling on Transport. A simple model has been developed to evaluate the effective diffusivity. It is assumed that the particles have uniform size and each particle is surrounded symmetrically by an equal amount of

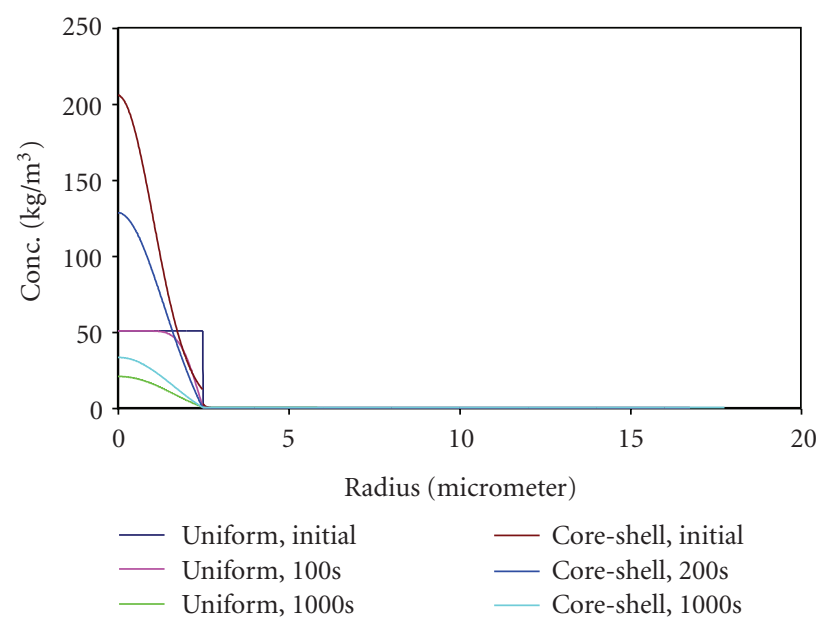

FIGURE 13: Inhibitor distribution of particles during the release process.

solution. As shown in Scheme 1, the particle has a radius of $r_{p}$ and the outer boundary of the solution surrounding the particle is $r_{L}$. The concentration of solute in the particle and solution are $C_{p}$ and $C_{s}$, respectively. The general diffusion equation (1) in spherical coordinates was used to begin the evaluation process:

$$
\frac{\partial C}{\partial t}=D \frac{1}{r^{2}} \frac{\partial}{\partial r}\left(r^{2} \frac{\partial C}{\partial r}\right)
$$

A numerical method is used to evaluate the effective diffusion coefficient, $D_{\text {eff }}$, by comparing the calculated $C_{s}$ - $t$ curve with the measured release profiles based on initial conditions (2) and boundary conditions (3). Using the Crank-Nicolson method and assuming a constant $D_{\text {eff, a }}$ matrix of the concentration profile at any time is obtained based on the initial conditions and boundary conditions. There is no limitation of $D_{\text {eff }} \delta /(\delta r)^{2} \leq 1 / 2$ for this method. The $C_{s}$ value is averaged by an integration method and plotted as a function of time:

$$
\begin{gathered}
C_{p}(r, 0)=C_{0}(r), \quad C_{s}(r, 0)=C_{s, 0}, \\
\left(\frac{\partial C_{p}}{\partial r}\right)_{r=0}=\left(\frac{\partial C_{s}}{\partial r}\right)_{r=r_{s}}=0, \\
D_{\text {eff }}\left(\frac{\partial C_{p}}{\partial r}\right)_{r=r_{p}}=D_{S}\left(\frac{\partial C_{s}}{\partial r}\right)_{r=r_{p}}, \\
C_{p}\left(r_{p}, t\right)=C_{s}\left(r_{p}, t\right) .
\end{gathered}
$$

A few factors such as the effective diffusion coefficients in the particles $\left(D_{\text {eff }}\right)$ and in the bulk solution $\left(D_{S}\right)$, particle size effect, dilution level, and distribution of the active corrosion inhibitor have been taken into consideration.

Figure 10 shows how external diffusion, $D_{S}$ (the diffusion in deionized (DI) water), affects the predicted release of $2.5 \mu \mathrm{m}$ particles with an uniformly distributed inhibitor. The dilution level, DI water/particle (weight), is kept as 100, and 


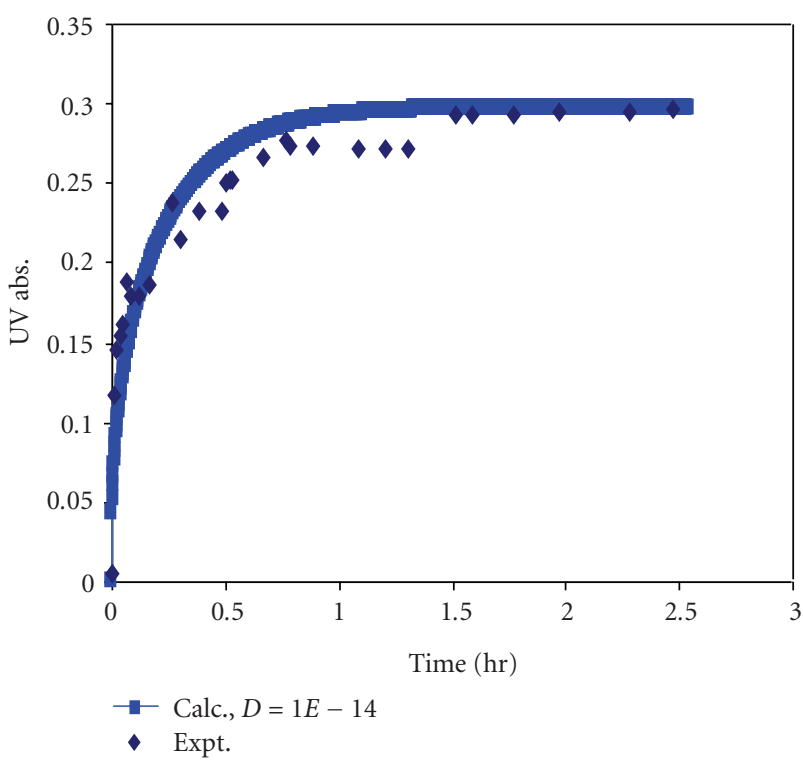

Figure 14: Release of Ce/silica particles in DI water.

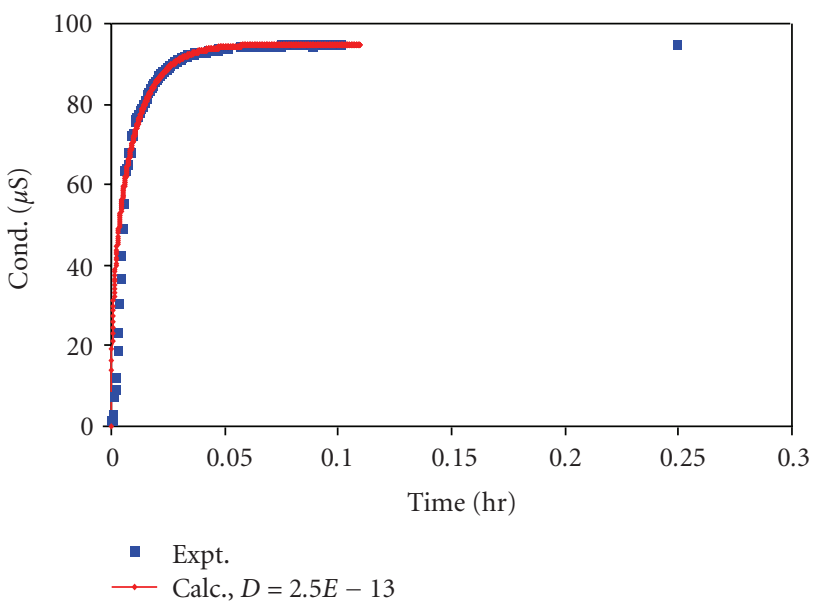

Figure 15: Release of NaCl/silica particles in DI water.

the internal diffusion coefficient, $D_{P}$, is set as $1 \times 10^{-15} \mathrm{~m}^{2} / \mathrm{s}$. We can see that external transport resistance can be negligible for a $D_{S} / D_{P}$ greater than 100 . The release curves are the same for the $D_{S}$ of a value of $1 \times 10^{-9}, 1 \times 10^{-10}$, and $1 \times 10^{-12} \mathrm{~m}^{2} / \mathrm{s}$. The diffusion coefficients of ions in water are within this range. For the release process, stirring does not speed the release as also evidenced by the experiment. There is no need to obtain the exact value for $D_{S}$. We can select a $D_{S}$ with a value $10^{-10}$ or $10^{-9} \mathrm{~m}^{2} / \mathrm{s}$ without compromising the accuracy of $D_{P}$ in the simulation. The internal diffusion has also been examined. Figure 11 shows the effect of $D_{P}$ on the release with a $D_{S}$ fixed as $1 \times 10^{-10} \mathrm{~m}^{2} / \mathrm{s}$. The characteristic release time is reverse to $D_{P}$. The particles with a higher $D_{P}$ show a quicker release. The release time also depends on the particle size. As shown in Figure 12, bigger particles show delayed release.

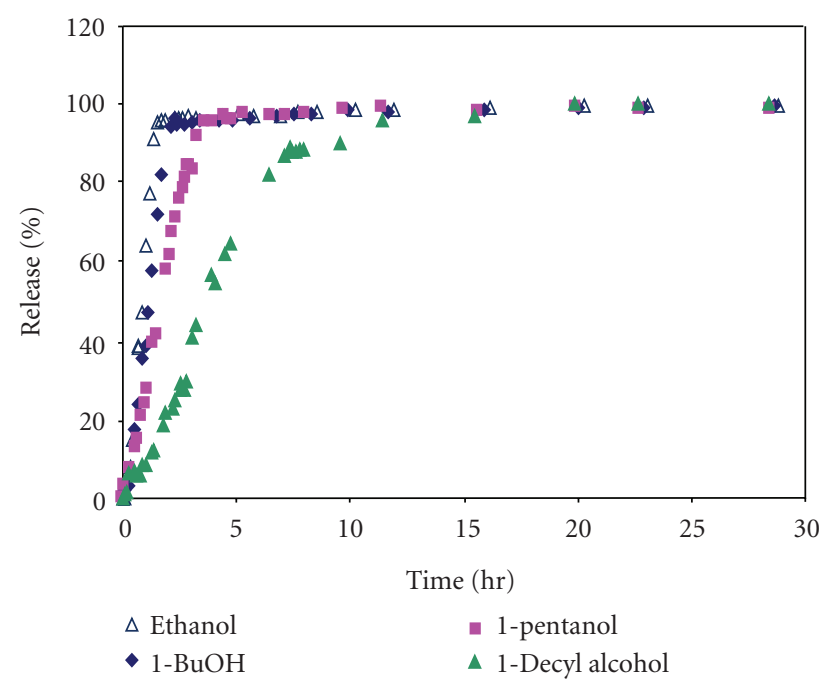

FIGURE 16: Ce release in alcohols for hydrophobic MTES-derived $\mathrm{Ce} /$ silica particles.

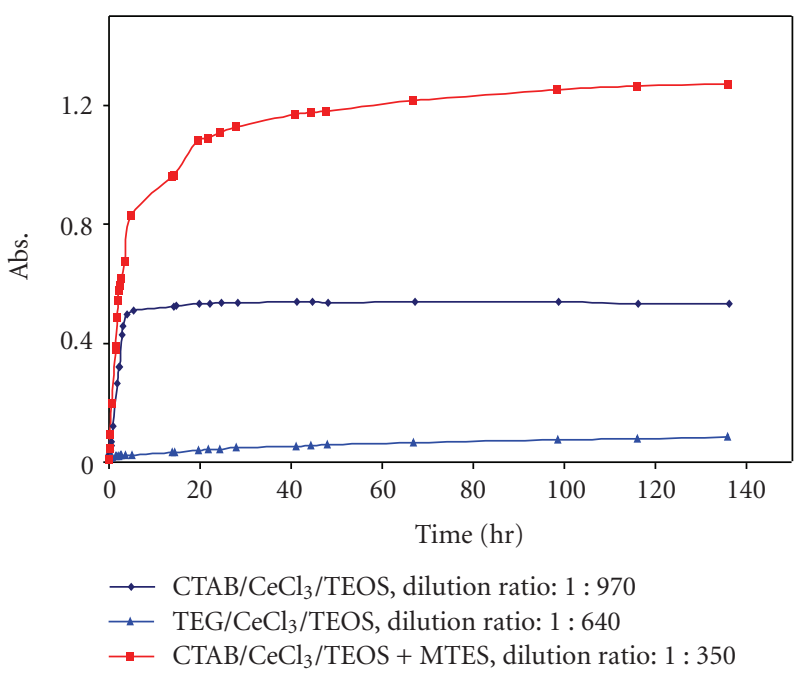

FIGURE 17: Effect of pore size and hydrophobicity on the release process.

Figure 13 shows simulated release results for $2.5 \mu \mathrm{m}$ particles using the same inhibitor loading. The $D_{S}$ was set as $1 \times 10^{-10} \mathrm{~m}^{2} / \mathrm{s}, D_{P}$ as $1 \times 10^{-15} \mathrm{~m}^{2} / \mathrm{s}$, and a dilution level of 100. Compared to uniformly distributed particles, core-shell structured particles demonstrated delayed release, giving them a much longer service time.

To elucidate, actual effective diffusion coefficients for monodisperse Ce/silica and $\mathrm{NaCl} /$ silica particles of $10 \mu \mathrm{m}$ were made by a vibrating orifice aerosol generator (VOAG), TSI Atomizer 3076. The particles were dispersed in DI water. The solution concentrations were characterized by measuring the conductivity or absorbance of the solution at different release times. The release profiles are shown in Figures 14 and 15 for $\mathrm{Ce} /$ silica and $\mathrm{NaCl} /$ silica particles, respectively. The effective diffusion coefficient is $2.5 \times 10^{-13} \mathrm{~m}^{2} / \mathrm{s}$ for $\mathrm{NaCl}$ and $1.0 \times 10^{-14} \mathrm{~m}^{2} / \mathrm{s}$ for $\mathrm{Ce}^{3+}$. 


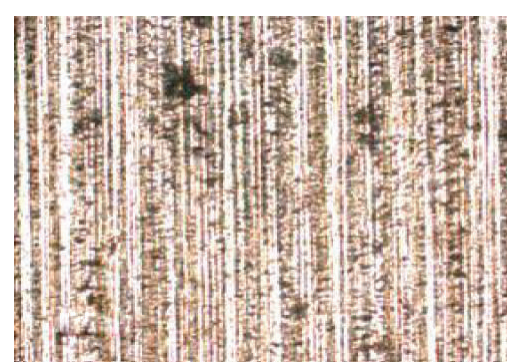

(a)

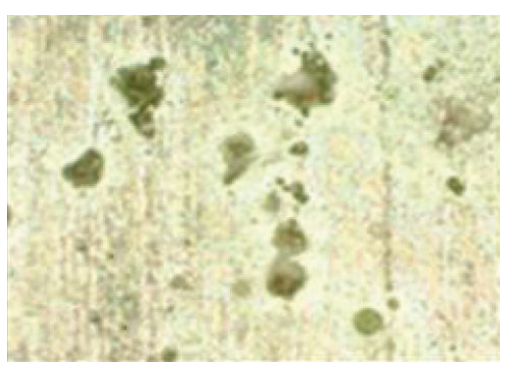

(b)

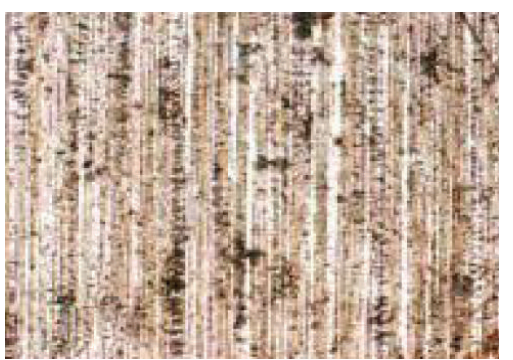

(c)

FIgURE 18: Optical microscopic images for aluminum alloy AA2024-T3 (scale bars $=25 \mu \mathrm{m}$ ). (a) Original uncorroded alloy. (b) Alloy corrosion after immersion in $0.05 \mathrm{M} \mathrm{NaCl}$ solution for $100 \mathrm{~h}$. (c) Alloy corrosion after immersion in $0.05 \mathrm{M} \mathrm{NaCl}$ and Ce/silica particle solution for $100 \mathrm{~h}$.

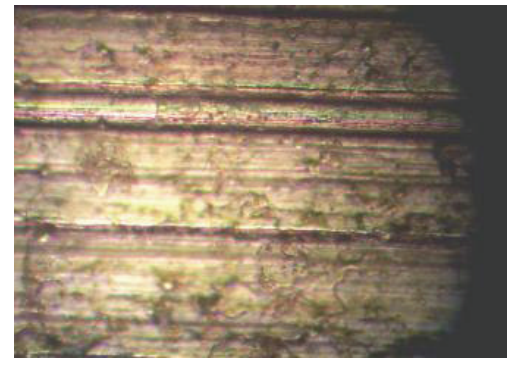

(a)

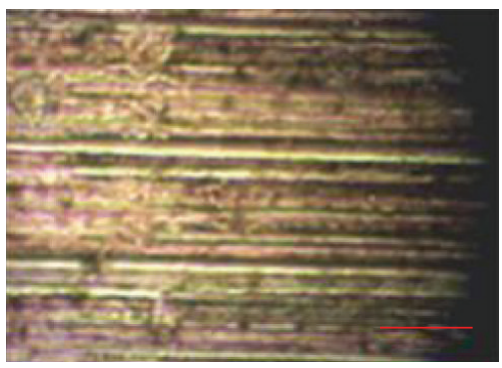

(b)

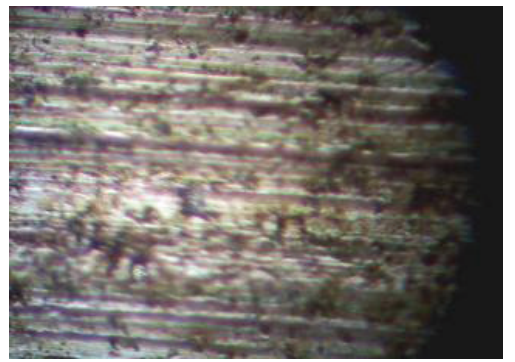

(c)

FIGURE 19: Optical microscopic images for aluminum alloy AA2024-T3 (scale bars $=25 \mu \mathrm{m}$ ). (a) Initial superhydrophobic Ce/silica-coated AA2024-T3 alloy. (b) Corrosion of superhydrophobic and Ce/silica-coated alloy after immersion in $0.05 \mathrm{M} \mathrm{NaCl}$ solution for $447 \mathrm{~h}$. (c) Corrosion of bare, uncoated AA2024-T3 alloy after immersion in $0.05 \mathrm{M} \mathrm{NaCl}$ solution for $447 \mathrm{~h}$.

The release behavior has been checked for the release rate in different n-alcohols. As shown in Figure 16, the constant release rate in various solvents over a long time suggests a solubility control for the release. The longer the solvent chain, the slower the release. The lower solubility and lower diffusion coefficient due to high viscosity account for the slower and straight release in high-carbon alcohols. For longterm corrosion inhibition, the inhibitors can be selected or converted to the form of suitable solubility in the corrosion medium. Highly soluble inhibitors are not a judicious choice from this point of view, but they may be if the inhibitor concentration is higher than the critical level required for inhibition.

Figure 17 shows release profiles for various Ce/silica particles. Methyltrimethoxysilane (MTES)/TEOS-derived hydrophobic particles and the microporous particles templated by triethylene glycol (TEG) demonstrated slow release. The estimated effective corrosion inhibition time for TEGtemplated particles is greater than $3000 \mathrm{~h}$.

The nanostructured core-shell Ce/silica particles were evaluated for corrosion inhibition of aluminum alloy AA2024-T3. As shown in Figure 18, without the nanostructured Ce/silica particles the alloy was easily corroded, and many pits were formed after $100 \mathrm{~h}$ of immersion in a $0.05 \mathrm{M} \mathrm{NaCl}$ solution; see Figure 18(b). However, dispersing $1 \mathrm{~g}$ of nanostructured silica particle $\mathrm{b}$ (Figure $1(\mathrm{~b})$ ) mixed into $100 \mathrm{~mL} 0.05 \mathrm{M}$ of $\mathrm{NaCl}$ solution efficiently inhibited corrosion (Figure 18(c)). A superhydrophobic coating layer containing the particles was also checked for corrosion protection. As can be seen in Figure 19, the coating protected the alloy well (Figure 19(b)). Without the core-shell particle coating, the alloy turned black and many pits appeared on the surface (Figure 19(c)). For comparison, the superhydrophobic coating without addition of the particles was checked for protection. Even though there was a lag time to sufficiently wet the sample, after being immersed in the solution for $447 \mathrm{~h}$, the sample containing only the superhydrophobic turned black as well. The controlled release of the particles' corrosion inhibitors inhibited the corrosion and selfhealed the corroded surface. This preliminary data clearly demonstrate the effectiveness of $\mathrm{Ce}^{3+}$ as corrosion inhibitor for protecting alloy AA2024-T3, because the inhibitor is releasable from the nanostructured particles.

Mathematical modeling for $\mathrm{Ce}^{3+}$ diffusion in the nanoporous particles demonstrated that the core-shell structure helps delay the release process compared to uniformly distributed $\mathrm{Ce} / \mathrm{silica}$ particles. The evaluated effective diffusion coefficient in water is $1.0 \times 10^{-14} \mathrm{~m}^{2} / \mathrm{s}$ at $25^{\circ} \mathrm{C}$. The experiment also proved that the release can be controlled effectively by pore size and pore surface chemistry. Longterm corrosion inhibition can be realized by particles with small and hydrophobic pores. But a denser and thicker coating is needed for a water/ion transport barrier. Further corrosion test is being conducted for the particles that are 
dispersed into a protective hydrophobic or epoxy coating layer for alloy AA2024-T3.

\section{Conclusion}

In conclusion, the nanostructured particles with a cerium core and mesoporous silica shell were synthesized via aerosol-assisted EISA and characterized using TEM, XRD, EPR, and so forth. We also demonstrated that the coreshell nanostructured particles were effective for corrosion inhibition of aluminum alloy AA2024-T3.

\section{Experimental}

4.1. Materials. All the chemicals were used as received. TEOS, MTES, cetyltrimethylammonium bromide (CTAB), $\mathrm{Ce}\left(\mathrm{NO}_{3}\right)_{3} \cdot 6 \mathrm{H}_{2} \mathrm{O}$, and $\mathrm{CeCl}_{3} \cdot 7 \mathrm{H}_{2} \mathrm{O}$ were obtained from Sigma-Aldrich (St. Louis, MO). Hydrochloric acid was VWR brand (VWR International, West Chester, PA), while absolute ethanol was obtained from Aaper (Brookfield, CT). DI water (Millipore, Billerica, MA) was used for all experiments. Aluminum alloy AA20240-T3 was obtained as a 3.0-mm-thick sheet from Davidson Aluminum \& Metal Corporation (Deer Park, NY).

4.2. Particles Synthesis. Silica/surfactant aerosols were generated using a commercial atomizer (Model 9302A; TSI, Inc., St. Paul, MN) operated with nitrogen as a carrier/atomization gas. The procedure was the same as described by Lu et al. $[14,15]$. It starts with a homogeneous solution of soluble silica, acid, and surfactant prepared in an ethanol/water solvent with an initial surfactant concentration much less than the CMC. The pressure drop at the pinhole was $20 \mathrm{psi}$. The temperature for three heating zones was kept at $400^{\circ} \mathrm{C}$. Particles were collected on a Durapore Membrane Filter maintained at $80^{\circ} \mathrm{C}$. The precursor sol molar ratio was 1 TEOS:7.7 EtOH:24.8 water:0.0125 $\mathrm{HCl}: 0.18 \mathrm{CTAB}: 0-0.24 \mathrm{CeCl}_{3}$. All calcination treatments were performed in a Lindberg tube furnace at $500^{\circ} \mathrm{C}$ for $5 \mathrm{~h}$ in forming gas $\left(7 \% \mathrm{H}_{2}\right.$ and $\left.93 \% \mathrm{~N}_{2}\right)$ at a heating rate of $1{ }^{\circ} \mathrm{C} / \mathrm{min}$.

4.3. Characterization. XRD spectra were recorded on a Siemens D-500 diffractometer, using Ni-filtered $\mathrm{Cu} \mathrm{K} \alpha$ radiation with $\lambda=1.5406 \AA$, a graphite monochromator, and a scintillation detector; data were refined using the JADE software package (Materials Data Inc., Livermore, CA).

TEM was performed using a JEOL 2010 HREM equipped with Oxford-Link X-ray energy-dispersive spectroscopy (EDS). A Gatan slow scan CCD camera was used for recording TEM images and electron diffraction patterns, operating at an accelerating voltage of $200 \mathrm{kV}$.

4.4. $\mathrm{N}_{2}$ Isothermal Sorption. Nitrogen isothermal adsorption was measured at $77 \mathrm{~K}$ on a Micromeritics ASAP 2010 porosimeter. Surface area was estimated by using the BET equation. The pore size was calculated using the BJH model.
4.5. EPR Spectroscopy. Electron paramagnetic resonance (EPR) analysis was operated using a Bruker Elexsys spectrometer with a microwave frequency of $9.8 \mathrm{GHz}$, a modulation amplitude of $10 \mathrm{GHz}(100 \mathrm{kHz})$, a receiver gain of $10^{4}$, and a time constant of $82 \mathrm{~ms}$. Samples were prepared by mixing ground pure $\mathrm{CeCl}_{3}$ or sample c with boron nitride. The standard sample made from pure $\mathrm{CeCl}_{3}$ had the same $\mathrm{Ce}$ loading as the sample $\mathrm{c}$ mixtures. The $\mathrm{Ce}^{3+} /\left(\mathrm{Ce}^{3+}+\mathrm{Ce}^{4+}\right)$ was calculated by the ratio of integrated EPR signals of sample $\mathrm{c}$ to the standard sample.

Release of $\mathrm{NaCl}$ and $\mathrm{Ce}^{3+}$ from the particles was characterized by measuring the conductivity or the absorption using a conductivity meter or an UV-Vis spectrometer.

4.6. Corrosion Inhibition Test. The corrosion inhibition of particles was checked by dispersing the particles in $0.05 \mathrm{M}$ $\mathrm{NaCl}$ aqueous solution. AA2024-T3 alloy coupons were immersed in the solution over $100 \mathrm{~h}$ followed by optical microscopy analysis.

4.6.1. Superhydrophobic Coating on AA20240-T3. Tetramethylorthosilicate (TMOS), methanol, ammonium hydroxide (35\% wt), 3,3,3-trifluoropropyltrimethyoxysilane (TFPTMOS), and DI water were mixed in a molar ratio of $1: 41.56: 0.003: 0.33: 5.85$. The mixture was stirred for $10 \mathrm{~min}$ and aged for $48 \mathrm{~h}$ at $50^{\circ} \mathrm{C}$. The formed gel was washed with hexane and ethanol for $2 \mathrm{~h}$. The gel was diluted with $1: 1$ ethanol and kept for sonification for reliquefaction. The redispersed sol was filtered through a $1 \mu \mathrm{m}$ glass fiber filter. The filtered sol was mixed with core-shell Ce/silica particles $(100: 1 \mathrm{wt})$ and was spin-coated at $200 \mathrm{rpm}$ for $20 \mathrm{~s}$ on a AA20240-T3 alloy substrate. AA2024-T3 alloy coupons with superhydrophobic coating containing coreshell particles were dipped in a $0.05 \mathrm{M} \mathrm{NaCl}$ aqueous solution for $447 \mathrm{~h}$ before optical microscopy analysis.

\section{Acknowledgments}

We thank Dr. D. L. Tierney, Department of Chemistry and Biochemistry, Miami University, for assistance with EPR. Also we thank Dr. Scully Jr. of the University of Virginia for the help with the corrosion test. This work was supported by National Science Foundation NIRT Grant: EE C-0210835, NSF: EF-0830117, the Air Force Office of Scientific Research Award Number F49620-01-0168, the DOD MURI Program Contract 318651, NIH: U19 ES019528 (The Center for Nanobiology and Predictive Toxicology at the University of California, Los Angeles), and the NIH/Roadmap for Medical Research grant PHS 2 PN2 EY016570B. Sandia National Laboratories is a multiprogram laboratory operated by Sandia Corporation, a Lockheed Martin Company, for the United States Department of Energy's National Nuclear Security Administration under Contract DE-AC04-94AL85000.

\section{References}

[1] M. A. Jakab and J. R. Scully, "On-demand release of corrosioninhibiting ions from amorphous Al-Co-Ce alloys," Nature Materials, vol. 4, no. 9, pp. 667-670, 2005. 
[2] J. V. Kloet, W. Schmidt, A. W. Hassel, and M. Stratmann, "The role of chromate in filiform corrosion inhibition," Electrochimica Acta, vol. 48, no. 9, pp. 1211-1222, 2003.

[3] M. W. Kendig and R. G. Buchheit, "Corrosion inhibition of aluminum and aluminum alloys by soluble chromates, chromate coatings, and chromate-free coatings," Corrosion, vol. 59, no. 5, pp. 379-400, 2003.

[4] R. L. Cook Jr., "Pigment-derived inhibitors for aluminum alloy 2024-T3," Corrosion, vol. 56, no. 3, pp. 321-333, 2000.

[5] P. Campestrini, H. Terryn, A. Hovestad, and J. H. W. de Wit, "Formation of a cerium-based conversion coating on AA2024: relationship with the microstructure," Surface and Coatings Technology, vol. 176, no. 3, pp. 365-381, 2004.

[6] M. Forsyth, K. Wilson, T. Behrsing, C. Forsyth, G. B. Deacon, and A. Phanasgoankar, "Effectiveness of rare-earth metal compounds as corrosion inhibitors for steel," Corrosion, vol. 58, no. 11, pp. 953-960, 2002.

[7] P. Traverso, R. Spiniello, and L. Monaco, "Corrosion inhibition of $\mathrm{Al} 6061 \mathrm{~T} 6 / \mathrm{Al} 2 \mathrm{O} 3 \mathrm{p} 10 \%(\mathrm{v} / \mathrm{v})$ composite in 3.5\% $\mathrm{NaCl}$ solution with addition of cerium (III) chloride," Surface and Interface Analysis, vol. 34, no. 1, pp. 185-188, 2002.

[8] B. Davó and J. J. De Damborenea, "Use of rare earth salts as electrochemical corrosion inhibitors for an Al-Li-Cu (8090) alloy in 3.56\% NaCl," Electrochimica Acta, vol. 49, no. 27, pp. 4957-4965, 2004.

[9] R. G. Buchheit, H. Guan, S. Mahajanam, and F. Wong, "Active corrosion protection and corrosion sensing in chromate-free organic coatings," Progress in Organic Coatings, vol. 47, no. 34, pp. 174-182, 2003.

[10] N. N. Voevodin, V. N. Balbyshev, M. Khobaib, and M. S. Donley, "Nanostructured coatings approach for corrosion protection," Progress in Organic Coatings, vol. 47, no. 3-4, pp. 416-423, 2003.

[11] T. L. Metroke, O. Kachurina, and E. T. Knobbe, "Spectroscopic and corrosion resistance characterization of GLYMO-TEOS Ormosil coatings for aluminum alloy corrosion inhibition," Progress in Organic Coatings, vol. 44, no. 4, pp. 295-305, 2002.

[12] T. L. Metroke, O. M. Kachurina, E. Stesikova, and E. T. Knobbe, "Composite coatings based on hybrid silicate and trivalent chromium conversion layers for aluminum alloy corrosion inhibition," Abstracts of Papers of the American Chemical Society, vol. 220, p. U341, 2000.

[13] A. Pepe, M. Aparicio, S. Ceré, and A. Durán, "Preparation and characterization of cerium doped silica sol-gel coatings on glass and aluminum substrates," Journal of Non-Crystalline Solids, vol. 348, pp. 162-171, 2004.

[14] Y. Lu, H. Fan, A. Stump, T. L. Ward, T. Rieker, and C. J. Brinker, "Aerosol-assisted self-assembly of mesostructured spherical nanoparticles,” Nature, vol. 398, no. 6724, pp. 223-226, 1999.

[15] Y. Lu, R. Ganguli, C. A. Drewien et al., "Continuous formation of supported cubic and hexagonal mesoporous films by sol-gel dip-coating," Nature, vol. 389, no. 6649, pp. 364-368, 1997. 

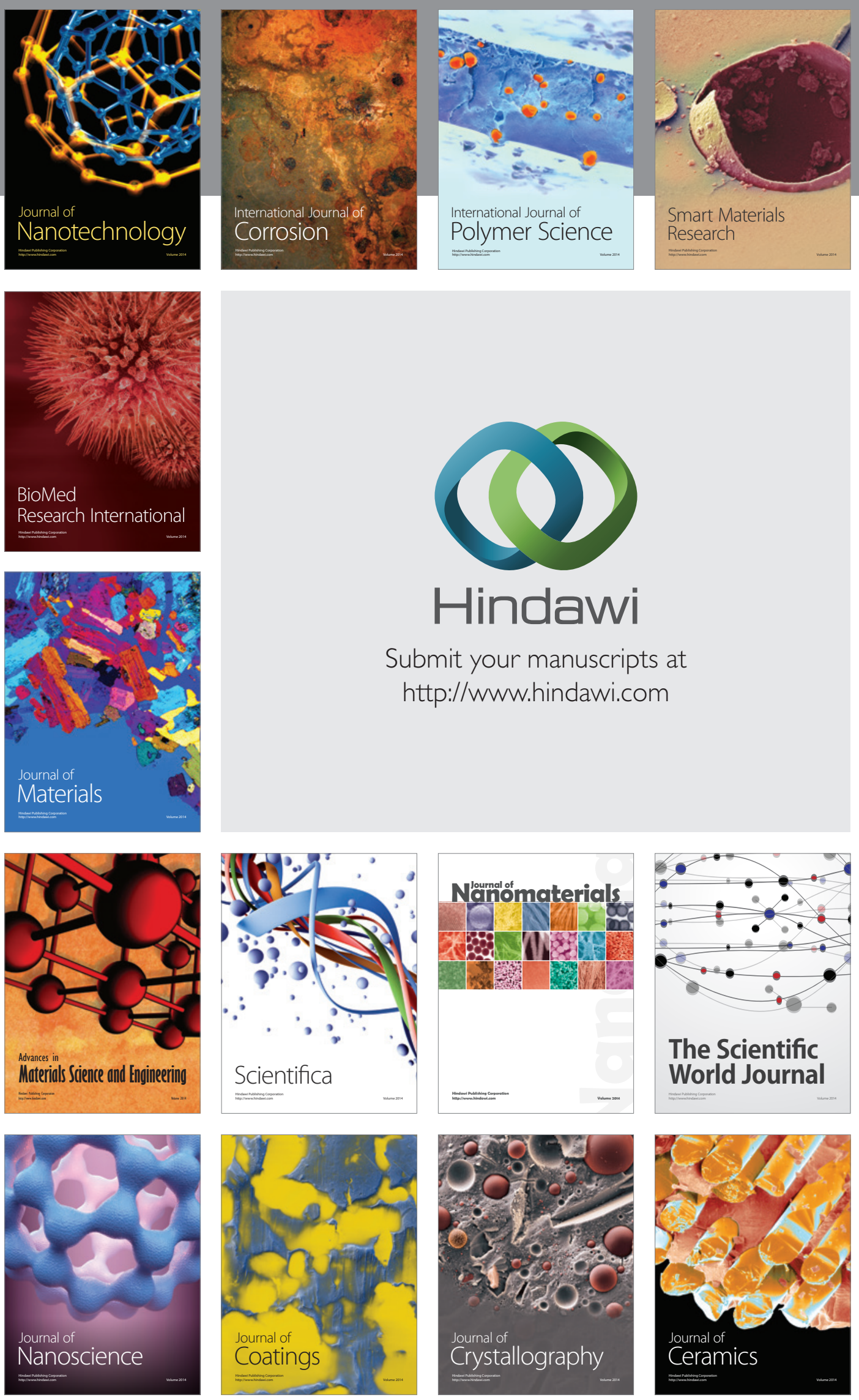

The Scientific World Journal

Submit your manuscripts at

http://www.hindawi.com

\section{World Journal}

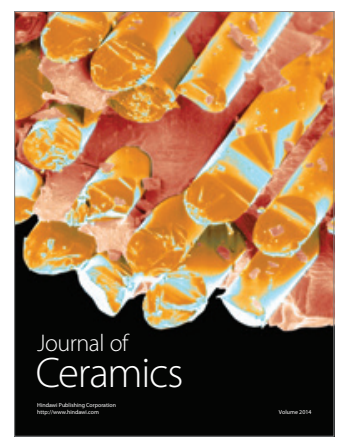

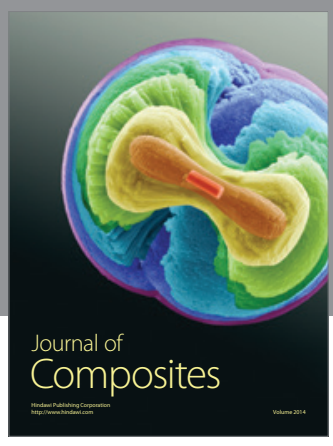
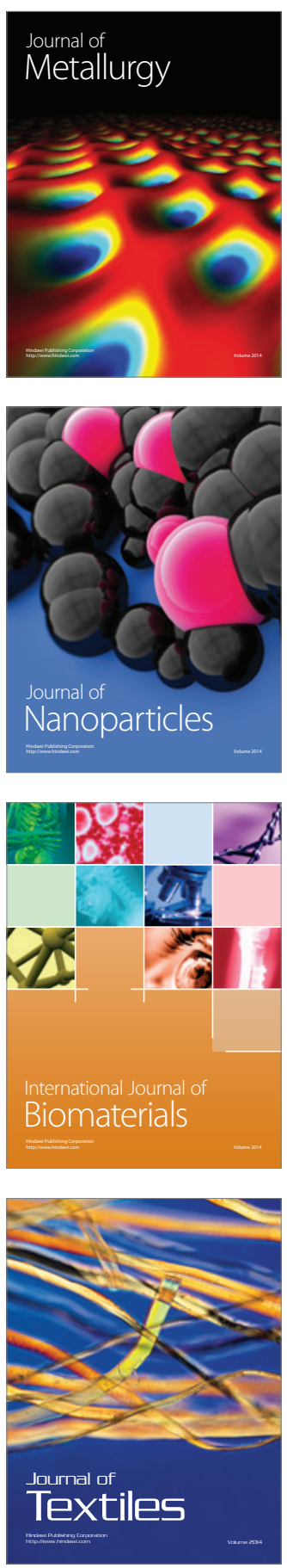